\title{
RESENHA BIBLIOGRAFICA
}

LA LINGUISTIQUE - Revue Internationale de linguistique générale $n .{ }^{\circ} \mathrm{l}, 1966$, Presses Universitaires de France. Diretor: André Martinet. Integram ainda a comissão diretora da revista: Emílio Alarcostlorach (Oviedo), Eric Buyssens), Henri Frei (Genebra), entre outros.

Publicação de grande interêsse e atualidade, pois ela se propõe examinar tudo o que se refere à linguagem e às línguas, em seu funcionamento como instrumentos de comunicação e de expressão, em suas variaçōes no espaço e no tempo, na ação que exercem umas sôbre as outras. Trata do lingüística geral, lingüística pura ou lingüística aplicada ou dos fatos particulares a uma língua ou a um grupo de línguas. Declara-se, no prólogo que não será a tribuna de uma determinada escola, mas recrutará seus colaboradores, em primeiro lugar, entre aquêles que procuram definir a estrutura de uma língua pelo exame do seu funcionamento. Mas, as pesquisas levadas a efeito hoje pōem o lingüista em contato não só com os filólogos, especialmente com a literatura, e também com os sociólogos, os psicólogos e outros, que tratam das diferentes formas do comportamento humano.

- presente número, de 155 páginas, estampa artigos sôbre os seguintes assuntos: 1. Forma e contexto na sintaxe, por Paul Garde. 2. A noção de sistema em Antoine Meillet, por Georges Mounin. 3. As teses transformacionais (Chomsky), por Blan che Grunig. 4. A estrutura do sistema de consoantes no Francês Canadense, por Alexander Hull. 5. Um ou dois fonemas?, por Jacques Veyrinc. 6. As diversas transcriçōes da língua Tarahumar e seu sistema fonológico, por André Lionnet. 7. A morfologia do russo falado, por Paul Garde.

ESSAIS DE LINGUISTIQUE GÉNÉRALE - por Romen JAKOBSON, Les Éditions de Minuit. Paris, 260 págines, traduzido do inglês : prefaciado por Nicolas Ruwet. Do matéri. inserida neste vulume, destacamos os se. guintes assuntos:

1 - Problemas gerais: 1. A linguagem co mum dos lingüistes e dos antropólogos conclusōes da conferência interdisciplinar realizada na Universidade de Indiane, em 1952. 2. Dois aspectos da linguagem e dois tipos de afasia. 3 . Os estudos tipológicos e sua contribuição à lingüística histórica comparada. 4. Aspectos lingǘsticos da tradução. 5. Lingǘística e teoria da comunicação. 11 - Fonologia: 1. Fonologia e Fonética. 2. Tensāo e relaxamento III - Gramática: 1. O aspecto fonológico e $n$ aspecto gra. matical da linguagem nas suas interrelações. 2. As calegorias verbais $e$ o verbo russo. 3. A noção de significação gramatical se. gundo Franz Boas.

IV - Poética. Lingüística e Poética. 
Há várics anos, Jakobson (atualmente com 70 anos de idade) dedica-se à elaboração de um grande tratado de lingüística geral, ao qual dará a título "Sound and Meaning". Sem dúvida, essa obra será um marco tão importante quanto c "Cours" de Saussure ou "Grundzüge" de Trubetzkoy. Uma Editôra de Haia empreendeu também a publicação de suas melhores obras em 4 idiomas (russo, alemão, francês, inglês).

\section{LA LINGUISTIQUE SYNCHRONIQUE - Étu.} des ef Recherches - por André Martinet. Presses Universitaires de France, o primeirs volume de uma série "Le linguiste", já anunciada:

1. Histoire de la Linguistique, des origines au XXe. siècle, por Georges Mounin. 2. La Linguistique du XXe. siècle, por Georges Mounin. 3. Le Bilinguisme, por Andrée Ta bouret-Keller.

4. Phonétique et Phenologie, por Jacqueline M.C. Thomas.

5. Les systèmes de signes, por Luis Prieto.

6. Le langage enfantin, por Emilio Alarcos. Llorach.

E o seguinte o conteúdo do presente solume:

1 - A dupla articulaçāo da linguagem: 1 . Natureza e caracterização da linguagem hu. mana. 2. O critério da articulação. 3. Arbitrário lingüístico e a dupla articulaçāo.

II - A Fonologia: 1. Fonética e fonologia.

2. Classificação e hierarquizaçāo dos fatos fônicos. 3. A análise fonológica.

III - Pontos de doutrina e de método em Fonologia: 1 . Trubetzkoy e o binarismo. 2. Trubetzkoy e os fundamentos da fonologia. 3. A fonologia e o sentimento lingüístico. 4. A fonologia e a linguagem infantil.

IV - Um ou dois fonemas? Substância fô. nica e traços distintivos. Acentos e tons. Saber para quem e porque se transcreve. Da variedade das unidades significativas.

$V$ - A hierarquia das oposiçōes significati. vas. As estruturas elementares do enunciado.

Alguns dos temas desenvolvidos aqui são totalmente novos; outros já foram tra- tados anteriormente, mas de maneira pouco acessivel, e por isso, receberam nova redaçāo e inovaçāo em alguns pontos ou foram considerados sob ângulo diferente.

\section{WOUK}

MARIANNE JOHANNA CHARLOTTE WALKER: "Die Poesie der Welt in den Grimm. schen Maerchen" (A poesia do mundo nos contos de fada dos irmãos Grimm). Tese para Livre-Docência apresentada à Cadeira de Língua e Literafura Alemã da Faculdade de Filosofia, Ciências e Letras da Universidade Federal do $P_{3}$ raná. 138 pgs. São Paulo, 1964, Graficor, Sociedade Editôra e Impressora Ltda.

No comêço do século XIX, na Alemanha, podia-se ver dois irmãos ocupados com um trabalho esquisito, o qual alguns bons elementos acharam e classificaram de indig. no. Jacob e Wilhelm Grimm foram por um lado filólogos, historiadores e também um pouco de filósofos, por outro lado eruditos e pesquisadores que trabalharam com grande exidāo. O que fizeram? Colecionaram contos de fada. E de fato, os irmäos Grimm percorreram cidades e aldeias, interrogaram gente velha, tomaram nota das histórias a êles contadas. Visitaram também camponeses nos arredores de Kassel, cidade onde os irmäos residiam. Accnteceu que um ou outro conto de fada foi narrado a êles à maneira diferente, o que cs Grimm chamaram de "variantes". Interrogaram também emprega das e pediam-lhes para falar no dialeto Mais tarde foram procuradas por pessoas de outras províncias as quais transmitiram-lhes novos contos de fada. Também pelo cor. reio recebiam essas histórias por escrito de todo país. E tudo isso resulteu no ano de 1812, no primeiro volume de "Kinder - und Hausmaerchen".

A tese reúne os seguintes capítulos: es. pecialidades na pesquisa de contos de fada - Origem e desenvolvimento dos contos populares de fada - Os irmãos Grimm e ? Romantismo Alemão - A natureza nos con- 
tos de fada - O fundo mitológico-divino

- O problema da poesia sôbre a natureza - O mundo real da alma infantil - Leis de estilo e forma como produto literário - 0 conto de fada no tempo e espaço. Com êste trabalho, a autora mostrou a capacidada de concentrar um tema tão amplo, sob aspecios modernos, e iluminar o reflexo da alma infantil nas obras imortais de Jacob e Wilhelm Grimm, contos que significam, ainda hoje, um dos últimos refúgios neste mundo, uma inconquistável fortaleza defen. dida pelas crianças com entusiasmo.

Reinaldo Bossmann

WALTER KOCH "Der Kolonist im Spiegel der Erzaehlungen des Koseritz-Kalenders (Versuch einer Deutung)" (O colono nas histórias do Almanaque de Koseritz) Tentativa de uma inferprefação". Tese para a Livre-Docência apresentada à Cadeira de Língua e Literatura Alemã da Faculdade de Filosofia, Ciências e Le. tras da Universidade Federal do Rio Grande do Sul. 117 pgs. Pôrto Alegre 1964, Editôra Meridional "Emma".

Esta publicação é uma boa contribuição para a história da imigração alemã no Rio Grande do Sul. Ela trata um tema sociolo. gico com entrelaçamentos psicológicos e his. tóricos. Neste trabalho nota-se muita aplica. ção e um estudo aprofundado do Almanaque de Koseritz. À página 63 é dito: "Deve-se observar, todavia. que Koseritz as utilizou (as histórias do calendário) para comunicar a sua ideologia...". Isto vale também para os outros autores dessas histórias do calen. dário. Nafuralmente, todo autor tem e quar transmitir algo aos seus leitores. Assim, é muito natural que as histórias sejam influ. enciadas pelas intenções do autor e colori das por sua ideologia. A pesquisa das in tençōes ideológicas em relação aos autores destas histórias do calendário só poderia ser de utilidade para esta tese.

Em relação à bibliografia apontada e utilizada, poder-se-ia dizer: Algumas destas publicações, principalmente dos anos de ..
1934 a 1942, devem ser observadas politicamente com cautela, uma vez que correspendiam à vontade da ideologia dos dominadores da Alemanha de então. Lembramos numa frase o triste capítulo entre VDA, Mi. nistério Rosenberg, Ministério de Propagan. da do Reich, e o Departamento de Himmler, por posiçōes de mando, ideologia nacional. sccialista que foram lançadas às costas dos alemães no estrangeiro e só lhes trouxeram descrédito ao nome honrado.

\section{Reinaldo Bossmann.}

MIGUEL ÂNGELO, Pôrto Alegre, 1964.

A cátedra de Língua e Literatura Italiana da $\mathrm{FFCl}$ da UFRGS promoveu as comemoraçōes do IV centenário da morte de Miguel Ângelo, e cuidou da publicação das conferências que foram pronunciadas. O Ciclo Comemorativo foi realizado na Escola de Eelas Artes da UFRGS e decorreu sob a responsabilidade e a orientação do Prof. Ângelo Ricci, catedrático de Língua e Literatura Italiana.

As conferências estiveram a cargo do Cônsul Geral da Itália em Pôrto Alegre, Dr. Alfredo di Mattei, (Michelangelo e il suo secolo); do Prof. Fernando Corona (Miguel Ângelo escultor); do Prof. Ângelo Guido (Miguel Ângelo pintor); do Prof. Carlos Antônio Mancuso (Miguel Ângelo arquiteto); do Prof. Ângelo Ricci (Miguel Ângelo poeta).

O Prof. Elpídio Paes traduziu 4 sonetos de Miguel Ângelo, que foram publicados no volume, juntamente com dois estudos, êstes devidos ao Bel. João Alberto Job (Miguel Ângelo no Renascimento), e ao Dr. Dionísio de Oliveira Toledo (Miguel Ângelo seu tempo e nossa época).

"A presente publicação que reúne todos êsses trabalhos - diz Antônio Loebmann na apresentação - deve-se à grata colaboração de umas entidades de Pôrto Alegre, e da Direção da revista "Estudos".

Luígi Casłagnola. 
ESTUdos SÓbre GaliLeo Galilei, Pôrto Alegre, 1964.

Sob a responsabilidade do catedrático de Língua e Literatura Italiana, Prof. Ângelo Ricci, foi organizada uma série de conferências comemorativas do IV centenário do nascimento de Galileo Galilei, na Faculdade de FCL da UFRGS, em Pôrto Alegre.

Foram ilustrados a época e os diversos aspectos de Galileo Galilei, astrônomo, matemático, físico, filósofo e escritor. As conferências foram pronunciadas por especialistas: Prof. Earle Macarthy Moreira (A Época Histórica de Galileo Galilei), Prof. Pedro da Rocha Andrade (Galileo Cientista), Prof. Dagmar S. Pedroso (Galileo Galilei e a Ciência Moderna), Prof. Gerd A. Bornheim (Galileo filósofo), Prof. Ângelo Ricci (Galileo Escritor).

A FFCL da UFRGS, a Secretaria da Educação do Estado do RGS e o Consulado Geral da Itália em Pôrto Alegre cuidaram da publicação das conferências. $O$ volume contém ainda, em apêndice, textos escoThidos de Galileo Galilei, traduzidos por Flávio Loureiro Chaves, e foi prefaciado pelo Cônsul Geral da Itália, Dr. Alfredo Di Mattei.

Esta publicação, digna de todo elogio, apresenta, através de estudos feitos por especialistas, os aspectos mais salientes do grande cientista, inventor do método experimental, e honra a FFCL da UFRGS, bem como o títular da Cadeira de Língua e Literatura Italiana, atualmente Diretor daquelo Faculdade.

\section{Luigi Castagnola.}

G. D. LEONI, "Literatura Universal - Esbôç̧o geral de uma história comparada das literałuras", Edições de Ouro, Rio de Janeiro, 1966.

Eis mais um precioso livro de bôlso, que as Ediçōes de Ouro oferecem ao público brasileiro. É devido à pena fecunda e competente do Prof. G. D. Leoni, catedrático das Faculdades de Filosofia da PUC de Săo Paulo e da Universidade Mackenzie.

O volume, artisticamente ilustrado, sintetiza "em poucas páginas a vastíssima matéria que costumamos definir com o título genérico de Literatura Universal", como diz - Autor na Advertência introdutiva. O conhecido Mestre paulista acrescenta mais uma bela publicação à quase fabulosa série de seus livros, sempre ricos de notícias com rara clareza e beleza de estilo.

O volume contém os estudos seguintes:

1 - Literaturas orientais.

2 - Literatura grega.

3 - Literatura romana.

4 - Literatura italiana.

5 - Literatura francesa.

6 - Literatura espanhola e hipano-americana.

7 - Literatura luso-brasileira.

8 - Literatura alemã.

9 - Literatura inglêsa e norte-americana.

10 - Literafuras menores.

11 - Esquema geral de uma história comparada das literaturas.

O volume termina com um índice onomástico.

Luigi Castagnola.

G. D. LEONI, "A Liferatura de Roma Esbôço Histórico da Cultura Latina com uma Antologia de Trechos Traduzidos", Editôra Nobel, 7.a edição, São Paulo, 1966.

As benemerências do Prof. G. D. Leoni, no campo didático e literário são muito conhecidas desde longos anos.

Esta sétima ediçāo da sua "Literatura de Roma" vem confirmar as qualidades de professor e de humanista do Autor. Tra. tando-se de livro já muito conhecido, queremos aqui destacar sòmente algumas palavras do prefácio: "A séfima edição dêste livro ... no seu sucesso editorial mostra claramente ainda uma vez a existência e necessidade de uma cultura clássica, base 
fundamental de qualquer estudo, quer literário quer científico".

Na tradução de alguns trechos contidos no volume colaborou a Professôra Neyde Ramos de Assis.

\section{Luígi Casłagnola .}

VERGílıo, "Eneida", Atena Editôra, São Paulo, 1966.

A coleção "Obras Imortais" da Editôra Atena foi enriquecida por mais êste belo volume, que será de grande utilidade para todos aquêles que cultivam as letras, especialmente as clássicas.

A obra-prima de Vergílio foi traduzida, em prosa, por G. D. Leoni e Neyde Ramos de Assis.

Ao lançar o volume, esplêndido também do ponto de vista tipográfico, a Editôra faz estas observaçōes: "Quanto a esta nova tradução, seja-nos permitido observar que cada meio século tem necessidade de apresentar em novas vestes os poetas e os prosadores antigos: não porque êles mudem mas porque nós sentimos diferentes necessidades estéticas e didáticas. Em nossa época a leitura da "Eneida" (...) com o comentáric de tôdas as minúcias seria fastidiosa e improfícua: eis porque quisemos apresen. tar uma narração em prosa, fácil a atraente, que tenha já implicitarıente resolvido os problemas de filologia segundo os resultados da crítica moderna".

- Prof. Leoni escreveu um "Estudo Introdutivo" sôbre Vergílio, suas obras e a época histórica em que viveu.

Foi acrescentado, no fim do volume, um "Glossário Mitológico e dos Nomes Próprios", que constitui, sem dúvida, novidade e será muito útil para todos os leitores.

Luígi Castagnola. 